\title{
El análisis fílmico: una historia de encuentro y de ética
}

\author{
Dimitri Weyl" \\ Psicoanalista, Doctor en psicopatología y psicoanálisis \\ Profesor de investigación en la universidad Paris 7, CRPMS
}

Recibido: 18 de diciembre 2017; aceptado: 15 de marzo 2018

\begin{abstract}
Resumen
Desde la mirada psicoanalítica, el arte cinematográfico es tomado -en la mayoría de los casos- ya sea desde una lógica de psicoanálisis aplicado, o bien en términos "isomórficos". Esto limita el aporte que el encuentro entre el cine y el psicoanálisis puede generar cuando estos dos campos son reconocidos con sus respectivas fuerza y singularidad. Este artículo propone identificar, sintéticamente, lo que se presenta como esencial en una perspectiva de investigación que posibilite que el análisis fílmico pueda ser lo más fructuoso posible. Walter Benjamin vio muy tempranamente que tanto el psicoanálisis como el cine abrieron campos visuales y auditivos de lo que no podía ser visto ni oído hasta entonces. Y que esos campos podían ser fuertemente complementarios. El lenguaje cinematográfico -cuando se lo reconoce con toda su fuerza- permite identificar efectos de lo real como ningún otro material permite hacerlo. Desde el inicio, nuestra hipótesis será considerar que unir armoniosamente la mirada cinematográfica con la mirada psicoanalítica es abrir un "doble foco". Dos focos que, al encontrarse, tienden a conectar lo invisible con lo visible. Lo invisible de los aspectos inconscientes a lo visible que abre la imagen-movimiento.
\end{abstract}

Palabras Clave: Análisis fílmico | Cine | Psicoanálisis | Imagen-movimiento

Film Analysis: a Story of an Encounter and of an etbic

\begin{abstract}
The psychoanalytical perspective on cinema most frequently adopts either the logic of applied psychoanalysis or an 'isomorphic' stance. This limits the contribution that the encounter between cinema and psychoanalysis might have to offer if both fields were approached from a stance which respects the individual power and respective singularity.
\end{abstract}

This paper presents a synthetic identification of what appears as essential in any research-based approach to this question, with an aim to making film analysis as fruitful as possible.

Walter Benjamin was quick to recognise that psychoanalysis and cinema opened up new horizons in both seeing and listening, in ways that could not hitherto be seen or heard. He also realised that these two fields could be powerful in their complementarity. The language of cinema -when its true eloquence is recognised- enables us to depict the effects of the real in ways that no other material can. yet this paper argues that exploring harmonious connections between the gaze of psychoanalysis and that of cinema means that a 'double focal point' is created. Two focal points which, when they come together, bind the invisible with the visible - the invisible of unconscious stakes with the visible of the image in motion.

Key Words: Film analysis | Cinema | Psychoanalysis | Image-movement

\section{Prolegómenos}

Me gustaría comenzar mi intervención con prolegómenos cortos que proporcionarán una base para mi propósito y lo incluirán al mismo tiempo en este tema de lucha, una lucha en la que la problemática de la imagen está fuertemente comprometida.

En la actualidad se desarrollan varias guerras de imágenes. Considero que la primera que viene a la mente hoy es la dirigida por Daesh. Esta guerra de imágenes utiliza procedimientos que están estrechamente relacionados, en gran medida inspirados, con los procedimientos de Hollywood. Podemos considerar, siguiendo a Marie José Mondzain, que el estilo de esta guerra de imágenes -su modo de operación- está marcado por un momento inaugural: el del 11 de septiembre de 2001, con Al Qaeda. Analizar, como lo hace Marie José Mondzain, que estos actos reales -de extrema violencia- se apoyan mutuamente y extraen su fuerza del poder de las imágenes inspiradas en los procesos de Hollywood nos lleva a considerar que esta guerra de imágenes está estrechamente relacionada con otra guerra de imágenes, más antigua, pero que sigue

dimitriweyl@icloud.com 
teniendo lugar. Es decir, algo que tiene que ver con lo que Debord descubrió en La Sociedad del espectáculo, desde 1967, siendo un gran visionario. Es decir, una política de lo espectacular que apunta a cautivar las miradas y las subjetividades, a deslumbrar, a sorprender, en definitiva, cuyo objetivo es que el espectador quede cautivo.

La guerra de imágenes de la que hablo -me sería imposible volver aquí a su arqueología- comenzó en la década de 1920, tomando nota del poder de las imágenes: las imágenes golpean más rápido y más fuerte que las palabras, tienen el poder de hacer creer, de ganar adeptos.

Se trata de la guerra que se libra entre las imágenes masivas, las imágenes en gran parte dominantes que se han vuelto literalmente omnipresente -entre las cuales las imágenes publicitarias me parecen paradigmáticas- y la imagen que es mucho más minoritaria: la imagen del arte. Las primeras tienden sobre todo a hacer vender, a hacer desear consumir, a convencer y a hacer creer -están completamente habitadas por lo que Lacan ha llamado el discurso del capitalismo- producen efectos de subjetivación; la segunda requiere la formación de una mirada, deja su libertad al espectador y puede contribuir a producir efectos de subjetivación. Hago aquí una partición esquemáti$\mathrm{ca}$, a la que evidentemente habría que darle mayor complejidad, por ejemplo, hablando de películas de piratas, de las cuales Scorsese informa en su historia del cine.

En todo caso, el cine está lejos de liberarse de esta conflictividad: es mayoritariamente una industria. $\mathrm{Y}$ es aquí más del cine artístico o al menos de aquel que plantea de lo que se llamó en Francia la política de los autores, del que me gustaría hablar. Un cine comprometido que participa en esta guerra de imágenes al colocar la mirada, la subjetividad -la del espectador y la del autor- la creatividad, la investigación, la emancipación -en última instancia la ética- en el corazón de su fabricación. Un cine que -como sostiene Rancière- deja al espectador en completa libertad.

Notemos que esta guerra -que trata de subjetividades-tiene algo eminentemente paradójico que la hace aún más operativa: vive en visibilidades masivas $y$, sin embargo, permanece muy a menudo invisible-como conflicto.

\section{Introducción}

Como resultado de estos prolegómenos, para introducir más directamente mi propósito y vincularlo al simposio celebrado en el verano de 2017 en Cerisy, titulado "El psicoanálisis y el cine: lo visible y lo decible", me parece interesante volver a una observación, hecha por Chantal Clouard y que, según me parece, fue ampliamente confirmada durante el simposio en cuestión. Chantal Clouard (que estuvo con Myriam Lebovici, coorganizadora) señala que podemos estar empezando a ver surgir en los últimos tiempos nuevas perspectivas sobre el encuentro entre el cine y el psicoanálisis. Hasta ahora, sin embargo, se pueden identificar tres tendencias recurrentes:

Una primera tendencia que se basa esencialmente en un enfoque analógico.

Una segunda tendencia que se basa esencialmente en la narratividad y que se ajusta -muy a menudo- del lado del psicoanálisis aplicado.

Finalmente, una tercera tendencia que pone en paralelo a la sesión analítica y la sesión cinematográfica. Me parece que podemos ubicar -más o menos- esta última tendencia en la primera ya que la analogía está fuertemente comprometida.

Lo que me interesó, al principio, en el análisis fílmico es aquello que puede enseñarnos -darnos para ver y sentir- un trabajo fílmico, algo que de otro modo no podríamos entender. Este enfoque me llevó a forjar un método y un enfoque epistemológico que me obligaron a abandonar estos registros porque parecían obstaculizar el poder del encuentro entre estos dos campos del conocimiento del hombre. Estos dos campos de conocimiento del hombre que hicieron posible mirarlo y escucharlo, y reflexionarlo como uno no podría hacerlo antes de estos dos descubrimientos sincrónicos. Esto es lo que Walter Benjamin sostuvo mucho antes (1936).

\section{Problemática}

En el análisis de películas, ¿cómo pueden el cine y el psicoanálisis reunirse con lo mejor de sus respectivos poderes?

¿Cómo el teórico, psicoanalista o refiriéndose al psicoanálisis, puede realizar un encuentro con el trabajo fílmico permitiendo avances teóricos?

Estoy de acuerdo con Mireille Berton cuando escribe en su reciente artículo: "La pareja cine-psicoanálisis, al igual que su corolario cine-sueño, continúan siendo aprehendidos aun hoy en términos del isomorfismo y de subordinación del primero al segundo".1

En esta línea identifico en el marco de los análisis fílmicos dos escollos que le son propios que pueden obstaculizar el encuentro: una relación de proyección, de do- 
minación sobre el cine y aquel que uno puede relacionar con la ilusión de gemelidad, sobre los cuales voy a tratar de ser breve.

\section{Psicoanálisis aplicado y superposición}

La lógica del llamado psicoanálisis aplicado puede significar e inducir el dominio absoluto de un conocimiento constituido sobre un objeto pasivo que, por lo tanto, no tiene a cambio ningún efecto, ningún efecto sorpresa. En la mejor de sus emanaciones, iluminamos el concepto, algo que a veces puede ser heurístico.

En la peor de estas emanaciones aplicar el psicoanálisis produce un efecto de enchapado abstracto, una relación de dominación, de posible confusión entre el concepto y la cosa, así como una asignación del objeto a la pasividad: el psicoanalista sabe y es con este saber que revelará lo invisible de la historia. Perdemos entonces-me parece esencial: lo que la obra toca de lo indecible, toca de real, toca de nuevo, de inesperado y de inexplorado.

\section{Exceso de aproximación analógica e ilusión de gemelidad}

El otro escollo puede ser el de la analogía excesiva que puede estar relacionada con la ilusión de gemelidad.

Una cierta cantidad de investigaciones, sobre el cine y el psicoanálisis, han trabajado -como sabemos- las contigüidades que se pueden identificar entre estos dos campos. Se habla de afinidades electivas de vocabulario como de proceso: proyección, sesión, pantalla, identificación, representación; la sala de cine donde se proyectan los sueños que analizamos y que sería comparable al proceso analítico, etc. Evidentemente, todos estos pasos no son totalmente denigrantes, especialmente cuando trabajan del lado de la analogía al tiempo que reconocen los límites específicos de la misma. Pero en el marco del análisis de películas, este paralelismo me parece bastante infructuoso.

Es precisamente en esto -creo- que podemos darle la razón a Freud: "Mi principal objeción (en lo que al cine se refiere) es que no me parece posible hacer de nuestras abstracciones una representación plástica que se respete $\tan$ poco". ${ }^{2} \mathrm{Si}$ "nuestras abstracciones" es igual o se refiere al inconsciente, parece efectivamente que el cine, no más que otro arte, no puede -estrictamente hablando-representar el inconsciente. Hay y habrá, muy probable- mente, siempre algo irrepresentable en el inconsciente.

La proximidad que se puede establecer entre el arte cinematográfico y los procesos primarios no le da el poder de representar el inconsciente. Sin embargo, esto no significa que el cine no sea capaz de captar y dar para ver y sentir algo de los conflictos inconscientes de una manera que le es absolutamente intrínseca.

En esta línea, el paralelismo más establecido es el del sueño, que también es válido para soñar despierto donde uno "se hace su película", analizar una película como si se tratara de analizar un sueño es -me parece- confundir una producción del inconsciente con la producción de una obra de creación, y de un investigador, que es -por una parte, significativa- consciente. Esto no excluye, por supuesto, que los procesos de condensación y desplazamiento sean esenciales en un trabajo fílmico.

\section{¿Los dos callejones sin salida clásicos del encuentro?}

En resumen, ¿los dos topes que acabamos de mencionar no se refieren acaso a aquello que probablemente evitará el poder de cualquier encuentro? Un exceso de distanciamiento que no reconoce el poder intrínseco del cine, la escritura fílmica y la forma en que puede cuestionar, interrogar, sorprender, e incluso modificar y enriquecer la mirada analítica.

Un exceso de proximidad, en el cual el régimen confusional tiende a disolver la singularidad, y por lo tanto el poder, de cada uno de estos campos.

Me parece más prometedor considerar -tal como dice Freud en la Gradiva- que las obras cinematográficas son "aliadas" y que es necesario seguirlas para dejarse sorprender.

Freud ha hablado así muchas veces del trabajo artístico como "adelantado" el trabajo del científico y, por lo tanto, no es un objeto de predilección, sino un precioso "aliado" del psicoanálisis. "Los escritores son preciosos aliados y debemos poner alto su testimonio porque normalmente saben muchas cosas entre el cielo y la tierra de las cuales nuestra sabiduría escolar no tiene la menor idea. Están por encima de nosotros, la gente común, especialmente en materia de psicología, porque provienen de fuentes que aún no hemos explorado para la ciencia". ${ }^{3}$

Así se juega, como en cualquier juego de encuentro, me parece, la problemática ética de la justa separación, de la distancia correcta, que supone reconocer -suficientemente- la alteridad y los puntos de unión de las dos entidades. 
Esto me lleva a considerar dos puntos de encuentro en los que la otredad, no obstante, está comprometida. Un primer punto que podría llamarse prehistórico y otro punto mucho más estructural.

\section{En las raíces de estos dos inventos se encontraba lo real de los cuerpos}

Podemos considerar que, al principio, o incluso en la prehistoria, en ambos campos de aprehensión del hombre estaba lo real de los cuerpos: Estos dos descubrimientos nacen por haberse interesado en los misterios del cuerpo cuya elucidación escapaba a las ciencias de la época. Algo que escapaba tanto a la aprehensión por lo simbólico como por lo imaginario. Uno va a trabajar para descifrar este real desde el lado de lo simbólico, el otro del lado de lo imaginario y ambos son nacidos de esta confrontación con lo real, con lo imposible, un irrepresentable, un a-sentido: no hay metapsicología sin clínica, no hay cine sin cuerpo real.

En la misma época que Freud fue testigo de las famosas puestas en escena de los cuerpos orquestadas por Charcot, Muybridge y Marey se pusieron a desentrañar el familiar misterio del movimiento corporal. Ambos se volverán famosos por sus trabajos de descomposición de movimientos corporales tanto de hombres como de animales que permitirán a los investigadores de la época darse cuenta que no se podía identificar claramente los movimientos de los cuerpos antes de la claridad ofrecida por la imagen-movimiento. ${ }^{4}$

Desde el principio hay dos miradas puestas en el hombre, sobre los cuerpos de los hombres, que tratarán de atravesar algo con puntos de vista que son de cierta manera opuestos. Uno desde su prehistoria, el cine, intentará atravesar algo del movimiento de los cuerpos mediante la creación de un aparataje que iluminará lo visible tal como no se podía ver anteriormente. El otro, el psicoanálisis, basará su descubrimiento explorando la ininteligibilidad de ciertos movimientos del cuerpo, los de la histérica, al clarificarlos por los problemas invisibles que los determinan. ${ }^{5}$

\section{Cineastas como investigadores}

Reconocer que los cineastas y las obras fílmicas pueden capturar cosas que no podrían capturarse sin ellos parece un requisito previo. Los realizadores son inves- tigadores, algunos específicamente en lo psíquico, tratando -en su mayoría- de comprender algo mediante la creación de un espacio fenomenológico que da a ver y sentir los impulsos y conflictos humanos. ${ }^{6}$

Muchos de estos cineastas -que mantienen nuestra atención en particular-se consideran investigadores sobre las relaciones humanas y lo psíquico Bergman, Buñuel, Losey, Pasolini, von Stroheim, Brisseau, Mankiewicz, etc. por nombrar solo algunos que han sido capaces de definirse a sí mismos en este sentido. Así, von Stroheim construirá su trabajo en conflictos humanos: "Tengo la intención de esculpir mis películas con la materia prima y ruda de los conflictos humanos". Mankiewicz, que estudió psicología, construyó casi todo su trabajo en problemáticas psicológicas que articulan el poder y el narcisismo.?

Otros incursionaron en ese continente oscuro. Brisseau cuando dirige Los ángeles exterminadores (2006), se empeña en filmar mujeres en escenas eróticas, sin juego, llegando realmente al orgasmo. Fuera y dentro de la película (puesta en abismo) Brisseau explica esta búsqueda contra viento y marea (escándalos y juicios): lo que lo anima por encima de todo es poder tomar, captar, entender algo del orgasmo femenino, poder fijarlo a través de la imagen-movimiento. A pesar del escándalo que generará, el proceso que intentarán hacerle, la gran dificultad para poder producir su película, él seguirá adelante. El impulso epistemofílico parece tener prioridad sobre las prohibiciones y se combina con el impulso escópico. ${ }^{8}$

Pasolini, para la producción de Edipo Rey (1967), se alimentó del conocimiento analítico para "re-proyectarlo" en un modo sensible. "Apliqué las nociones psicoanalíticas tal como las sentía y así es como re-proyecté el psicoanálisis sobre el mito". ${ }^{9}$

Buñuel, por su parte, parece responder y completar la cita que Freud extrae de la Gradiva, y que hemos citado anteriormente, y además señala algunas particularidades específicas del séptimo arte y el poder emocional de la imagen: "El cine es el mejor instrumento para expresar el mundo de los sueños, de las emociones, del instinto, y parece haberse inventado para expresar la vida del subconsciente cuyas raíces penetran tan profundamente en la poesía". ${ }^{10}$ Así para Luis Buñuel, el cine fue inventado para expresar -y no representar- los movimientos del inconsciente, cuyas "raíces", "fuentes" misteriosas para la "ciencia" evocada por Freud, están directamente vinculadas a la "Poesía", o quizás, lo que llamaremos más tarde poiesis. Siempre en la Gradiva, Freud escribe: "Nuestro modo de proceder consiste en la observación consciente, en los otros, de los procesos psíquicos que se 
desvían de la norma para poder adivinar y establecer sus leyes. El escritor, procede de manera diferente; es en su propia alma que dirige su atención al inconsciente, que observa sus posibilidades de desarrollo y les da una expresión artística, en lugar de reprimirlos con una crítica consciente. [...] Pero no necesita formular estas leyes, ni siquiera necesita reconocerlas con claridad; porque su intelecto las tolera, están encarnadas en sus creaciones". ${ }^{11}$

Bergman, a su vez, podría entrar en resonancia con Freud y al mismo tiempo dejar escuchar, él también, una especificidad cinematográfica.

"No bace falta decir que el cinematógrafo se convirtió en mi medio de expresión. Me hacía entender en un lenguaje que no pasaba por el lenguaje que me hacía falta, por la música que no dominaba, por la pintura que me dejaba frío. De repente tenía la posibilidad de relacionarme con el mundo que me rodeaba en un lenguaje que se habla directamente de alma a alma en giros que, casi voluptuosamente, eludían el control del intelecto. Así, (...) durante veinte años, sin cansarme, con una especie de furia, transmití sueños, sensaciones, fantasmas, crisis de locura, neurosis, estasis de la fe y de puras mentiras". ${ }^{12}$

Picasso podría completar: "El arte es una mentira que nos permite revelar la verdad". En otras palabras, el arte no revela lo real a través de la representación, ficciona, tuerce lo real para revelar algo que le es propio. La ficción es una elaboración creativa. Es un trabajo de la mente, de la imaginación creativa, a partir de datos, de materiales de vida utilizados y transformados para la construcción de una obra. ${ }^{13}$

No se trata más de rentar en un pseudo-misticismo, una forma de "fundamentalismo del arte": los grandes autores no son magos en fase con lo divino. Por el contrario, tienen una gran capacidad de elaboración y de puesta en forma.

\section{El Imaginario creativo}

Esta aparición de una forma-que esté en adecuación con el fondo- se relaciona con la poiesis del imaginario creativo. $^{14}$

Mientras que algunos cineastas tratan de desentrañar los misterios de la psiquis, es por el dar a tener y a sentir, a través de lo que Cornelius Castoriadis llama la imaginación radical, creativa, que es adecuado hacer emerger la poiesis. El término poiesis se refiere a una dimensión intrínsecamente creativa (poiese) de producción, de surgimiento, de intuición. Entiendo por poiesis una acción que conduce a una nueva creación, recurriendo al imaginario creativo.

Lo que Castoriadis denomina imaginario creativo o radical es la "facultad original de plantear o de darse, en el modo de la representación, una cosa y una relación que no están (que no están presentes en la percepción o que nunca lo estuvieron) [...]. El imaginario del que hablo no es imagen $d e$. Es una creación incesante y esencialmente indeterminada de figuras / formas / imágenes, a partir de las cuales solo puede ser cuestión de "algo", ${ }^{15}$ de una emergencia. El imaginario creativo conjuga los procesos primarios, pasando por la condensación y el desplazamiento, con la combinatoria creando nuevos arreglos e incluso surgimientos. No es la prerrogativa del artista, se trata de su fuente principal.

Y a este respecto, uno puede considerar legítimamente que Freud peca de exceso de modestia cuando parece limitar el trabajo del investigador psicoanalista, y limitando su propio trabajo a "una sabiduría escolar". Entonces, cuando escribió esta oración, que recoge una dimensión esencial de todo lo que acabamos de mencionar: "De hecho, hay un camino que permite el retorno de la imaginación a la realidad y es el arte", ${ }^{16}$ es evidente que sabe algo al respecto. Freud convoca muchas metáforas eclécticas en su trabajo. "Lejos de ser un mero decoro formal, el poder de la creación metafórica en el texto freudiano es proporcional al poder del pensamiento: es casi el síntoma mismo". ${ }^{17}$ Este no es un gran secreto: cada gran pensador es un artista, y cada gran artista es un pensador de envergadura. Nietzsche, para quien el aforismo, la metáfora, era un modo casi constante de expresión, se encuentra entre aquellos que más se acercaban a una síntesis entre el pensador y el artista. Aquí, entonces -en el seno del proceso de creación- las fronteras son borrosas y los paralelos se cruzan.

Por supuesto, el trabajo de las poietics está eminentemente trabajado en el proceso analítico y especialmente en los momentos de la interpretación performativa. Y si en el trabajo de la teorización la razón a menudo se mantiene en lo alto -por necesidad de orden e inteligibilidad-, solo la poietic permite avances reales, saltos cualitativos.

Dos procesos de los investigadores, por lo tanto, que en sus obras pasan, uno más por la razón, por el dar a entender, por la conceptualización y la teorización; el otro por el imaginario creativo, para darlo a ver y sentir. El teórico creó conceptos, el artista, para usar una terminología deleuziana, percepciones. ${ }^{18}$

Después de estos puntos de unión en sus diferencias, parece fundamental reconocer una otredad irreductible, 
constitutiva del poder cinematográfico. Este es el desafio ético: reconocer lo que el cine puede implicar el reconocimiento de una escritura propia.

\section{Escritura intrínsecamente cinematográfica o escritura fílmica}

Tenemos tendencia en el análisis de películas, como especialistas del habla, a centrarnos exclusivamente en las palabras y la narrativa en detrimento de las imágenes y el lenguaje cinematográfico. Si en el proceso de creación debemos reconocer, generalmente, tres tiempos de escritura: el escenario (incluido el guión gráfico), la filmación (o rodaje) y la edición, es por supuesto la entidad finalizada, la obra cinematográfica, que debe ser el tema del análisis.

Reduzco aquí los constituyentes de este lenguaje en su médula sustantiva y no pretendo -lejos de allí- un trabajo exhaustivo sobre este punto y en ese contexto. Se trata de identificar lo que parece esencial para el análisis fílmico.

\section{Los principales constituyentes}

Esta escritura fílmica se basa entonces en la imagen-movimiento, la imagen-tiempo, el encuadre fijo o móvil (panorámico y seguimiento) en tomas que pueden ser estrechas o anchas, o incluso secuencias de tomas, el montaje, la elipsis, el tratamiento del sonido y la luz, el fuera del campo.

También se podría considerar legítimamente que el procesamiento del sonido ocupa un lugar tan esencial que probablemente sea más preciso hablar, en muchos casos, de imagen-movimiento-sonido.

Si seguimos a Deleuze el primer constituyente fundamental del arte cinematográfico es la imagen-movimiento, es decir, una imagen que permite ver y sentir los movimientos, las secuencias sensorio motoras o las secuencias de actitudes y de posturas: todo lo que se desarrolla ante los ojos se inscribe en una secuencia causal.

La imagen-tiempo, por su parte, pertenece al tiempo en estado puro: se despliega una duración que no parece articularse con eventos, sin movimiento o un movimiento que es similar a una errancia. Estos son fenómenos en la pantalla que pueden provocar la sensación de ser inútiles, de no encajar de inmediato en una causalidad directa, en la lógica dramática manifiesta, son significativos en el après-coup.
Es necesario considerar que la condensación ocupa un lugar esencial en este lenguaje y que cada uno de estos elementos antes mencionados, que llamamos modos de expresión, gramática cinematográfica o herramientas intrínsecas, tiene un uso, dentro de una obra, necesariamente significativo. Que toda intención sea necesaria y no contingente en el arte, incluida aquella que se deja al azar, parece obvio, lo es también para el cine. No hace falta decir, por ejemplo, que uno no encontrará una pintura o una escultura de este o de aquel maestro diciéndose que este o aquel elemento de la obra es contingente. Esto es igualmente válido para una obra cinematográfica: podemos considerar cada plano, cada encuadre, cada composición espacial, el uso de fuera de campo, cada elipsis, cada edición, el procesamiento de luz y sonido, etc. como siendo significativos y estando relacionados, en $\log 0{ }^{19}{ }^{19}$ entre sí.

Así es que, no solo la condensación, que se refiere a la metáfora, sino también el desplazamiento, refiriéndose a la metonimia, deben ser considerados como "hiperactivos" ${ }^{20}$ en el arte cinematográfico. Es decir, que cada plano es potencialmente sobresignificativo y poderosamente polisémico, dado que también se refiere a otras cosas, a otros "significantes" en el seno de la obra, y por lo tanto realiza de este modo desplazamientos, que incluso pueden desarrollarse como rizomas. ${ }^{21}$

\section{El significante imaginario o no fonemático}

El trabajo de Christian Metz sobre lo que él llamó El Significante Imaginario, ${ }^{22}$ tendía a mostrar la especificidad de esta "unidad de lenguaje visible" en el arte cinematográfico.

Le P'tit bal perdu, cortometraje de Philippe Découflé lo utiliza de manera poética, ilustrando magníficamente el vínculo entre el significante y el significante imaginario. ${ }^{23}$

Como la materialidad del significante es diversa, este no es solo fonemático, puede también pasar por una imagen, una imagen-movimiento, una imagen-tiempo, un sonido, un objeto, un color o incluso la expresión de un rostro. ${ }^{24}$

Por lo tanto, tendería a preferir esta última expresión de "significante no fonemático" 25 porque no restringe su alcance a la imagen, incluye el sonido, cuya importancia capital ya fue mencionada.

Como sabemos, el significado se despliega completamente solo en la relación que una significante toma con otros significantes y esto es en la misma medida válido para el significante no-fonemático. Lo que nos lleva a 


\section{El montaje}

El efecto Kuleshov, que lleva el nombre del cineasta y teórico ruso, revela perfectamente eso a través del montaje: el mismo plano corto del rostro del actor Mosjoukine, inexpresivo, va precedido por un plano de plato de sopa, o un cadáver en un ataúd, o una mujer acostada lascivamente, formando tres secuencias cortas diferentes. El espectador traduce la expresión de Mosjoukine, alternativamente según la secuencia, por un sentimiento de hambre, de tristeza y finalmente de deseo sexual.

Por su parte, Godard nos dice "no es una imagen única, es únicamente una imagen”. Una imagen nunca está sola. Lo esencial está en la relación entre imágenes. Una imagen-movimiento despliega su precisión solo cuando entra en contacto con las otras imágenes de la película y finalmente solo toma su valor total cuando se constituye en parte de un todo, ya que la parte revela algo del todo, de la entidad que constituye la película, o incluso de la obra del autor en su conjunto. A veces, es probable que un plano no logre esclarecerse por completo cuando está solo en relación con todas las demás imágenes-movimiento de la película, sino que lo hace cuando se conoce la integralidad de toda la obra del autor; montaje de la película, construcción de la obra.

\section{El encuadre}

Cuando Dreyer filma a Renée Falconetti, en La pasión de Juana de Arco (1927), y encuadra en un plano corto (o primer plano) una toma de las más bellas y famosas de la historia del cine, lo que él nos da para ver y sentir, nunca había sido visto ni sentido por el ser humano.

El encuadre nos permite mirar la cara de Renée Falconetti, en una proximidad y en una distancia que despliega una "profundización de la apercepción". ${ }^{26}$

No se trata de la percepción de su rostro -"El propósito del arte, con los medios materiales, es arrancar la percepción de las percepciones del objeto" ${ }^{27}$ - sino de estar en ese rostro sin fundirse en él. Estar en ese rostro como uno estaría en "un bloque de sensaciones compuesto de perceptos y afectos". Vemos y sentimos una carga condensada e inefable.

"La obra de arte es un bloque de sensaciones, es decir, un compuesto de perceptos y de afectos. Los perceptos ya no son percepciones, son independientes del estado de quienes los experimentan", ${ }^{28}$ pues "la obra de arte es un ser de sensación, y nada más: existe en sí misma.” ${ }^{29}$
Quisiera dar testimonio, muy brevemente, sobre este poder del arte cinematográfico a partir de una puesta en paralelo con una de mis prácticas clínicas. En la Maison Verte, un lugar donde se atiende a niños de entre 0 y 4 años, la dimensión fenomenológica está constantemente en funcionamiento, en el corazón de nuestra práctica que involucra al psicoanálisis. Por tal motivo, todo lo que se puede dar para ver y sentir en una película como Recreación, o como Ser y tener, ${ }^{30}$ sobre los movimientos de los cuerpos de estos niños, la manera en que sus problemas psíquicos producen y atraviesan esos movimientos corporales, nunca podríamos experimentarlo, recibirlo, verlo y sentirlo con tanta agudeza; una presencia tal de estos cuerpos que no convoca a nuestros propios cuerpos en una interacción, sino dejando espacio para el afecto y las sensaciones, así como también lugar para el pensamiento. Al pensamiento en la medida que a estas imágenes las podemos ver y volver a ver, como materia reflexiva, como perceptos, y con la posibilidad de convocarlas cuando lo deseamos para pensarlas.

\section{Conclusión: El encuentro de las miradas}

En un pasaje significativo de su famoso texto "La obra de arte en el momento de su reproducibilidad técnica”, el cap. XIII, Walter Benjamin reconoció, muy temprano, la agitación producida por estos dos descubrimientos, cada uno en su singularidad. Benjamin escribe que estos dos descubrimientos sincrónicos han revolucionado la mirada del hombre, la mirada que el ser humano podría tener sobre sí mismo y sobre sus semejantes.

Ambos darán a mirar y escuchar lo real, de una manera que no podía ser visto ni oído anteriormente. Tanto para la gemelidad, como para lo sobresaliente, vamos a preferir la metáfora de los gemelos: el psicoanálisis, como el cine, permiten ver, no en el sentido del ojo, sino de la mirada, ${ }^{31}$ la modificación de las miradas. Dejemos aparecer la metáfora: incluso muestran de manera exacerbada lo que a menudo no podía ser visto.

Lo que marca la obra de arte es esta singularidad afirmada, esta brecha que abre tanto por ser única, como por no parecerse a ninguna otra, inscribiéndose en un universo propio del autor, de su mirada, y que posee, en sí misma, su propio universo, mientras toca a lo universal en el sentido de que cierne un efecto de lo real, incluso si lo toca o lo perfora en un punto y en una forma que ninguna otra forma podría haber tocado.

El arte cinematográfico tiende a definir puntos de 
inefable por la escritura cinematográfica. Puntos de inefable: lo que las palabras no sabrían decir; o que dirían de manera diferente.

En un nivel fenomenal, se muestran, a través de la imagen-movimiento, la imagen-tiempo, la disposición de significantes no-fonemáticos, encuentros, accidentes, estados de cambio y deseo en movimiento que se dan a ver y a sentir en una temporalidad -puntuada por la elipsis- y una espacialidad en el seno de las cuales la condensación, el desplazamiento, el punto de vista ocupan una parte esencial. ${ }^{32}$

El encuentro al que se apunta, entre el investigador psicoanalista y la obra cinematográfica, es la forma en que esta obra identificará un mismo punto de imposibilidad, un efecto de la realidad, a través de sus herramientas intrínsecas a la investigación y a la expresión artística. Y además tal vez, aunque más raramente, lo que la obra ha identificado y que el psicoanálisis no pudo captar o no pudo captar de otra manera que a través del lenguaje cinematográfico que emana de la mirada del autor de esta obra.

"Si está buscando lo que, en realidad, es más real que la realidad misma, mire del lado de la ficción cinematográfica". ${ }^{33}$

"Está muy claro, por lo tanto, que la naturaleza que le habla a la cámara no es la misma que la que les habla a los ojos. Es distinta, especialmente porque, el espacio donde domina la conciencia del hombre, es sustituido por un espacio donde reina el inconsciente. A menudo se puede observar, brevemente, el andar de un hombre, ciertamente no sabemos nada de su actitud en la fracción de segundo en la que alarga el paso. Sabemos más o menos el gesto que haremos para agarrar un encendedor o una cuchara, pero no sabemos mucho sobre el juego que realmente tiene lugar entre la mano y el metal, y mucho menos los cambios que se introducen en estos gestos, fluctuación de nuestros diversos estados de ánimo. Es aqui que la cámara penetra, con sus medios auxiliares, sus inmersiones y sus ascensos, sus cortes y sus aislamientos, sus ralentizaciones y su aceleración del movimiento, sus ampliaciones y sus disminuciones. Por primera vez, nos abre el acceso al inconsciente visual, como el psicoanálisis nos abre el acceso al inconsciente pulsional." ${ }^{34}$

Aunque no podemos reducir el inconsciente freudiano al "impulso inconsciente" y la fórmula del "inconsciente visual” nos parece psicoanalítica-mórfica, lo que retenemos del paralelismo de Benjamin es haber visto, de manera muy temprana, que el psicoanálisis y el cine abrieron campos de mirada y de escucha de aquello que, hasta entonces, no podía ser visto y oído. Y que estos campos podían ser poderosamente complementarios.

Esto hace que me guste mucho la idea de que vincular el cine y el psicoanálisis de forma complementaria es abrir una doble focal. Dos lentes que cuando se encuentran tienden a articular lo invisible a lo visible. Lo invisible de las cuestiones inconscientes con lo visible que abren la imagen-movimiento y la escritura fílmica. El psicoanálisis captura en lo invisible lo que es inexplicable en lo visible, el cine hace visible y sensible lo que no podría existir sin él.

La ética, tanto como la fecundidad del encuentro, se sostiene en un reconocimiento de los poderes respectivos de estos dos campos del conocimiento del hombre que colocan a la subjetividad en el corazón de la práctica analítica como de la creación artística.

\section{In fine, el encuentro subjetivo}

Lo invisible que el cine puede hacer visible se vuelve inteligible solo por el encuentro de las miradas. Mirada del cineasta, que permite ver y sentir a través de la escritura fílmica. Mirada del espectador, actor, activo, investigador, que se devela al encontrarse con la mirada del autor. ${ }^{35} \mathrm{El}$ efecto del encuentro involucra entonces necesariamente la subjetividad del espectador y la del investigador. Quien dice mirada dice subjetividad.

Serge Daney dijo que "una película nos concierne al menos tanto como la miramos”.

Mirar una película es potencialmente subjetivante. Las películas que encontramos nos conciernen, nos reflejan y nos alteran.

Esas películas que nos conmueven, no nos conciernen como idénticos, su mirada no remite a lo mismo, que fija y vuelve estático. Si hay un encuentro profundo y abrumador, es porque estas películas nos alteran, nos conmueven. Conciernen nuestra alteridad, ajena a nosotros mismos.

Traducción al español: Sergio Peralta

1 “Freud y la intuición cinematográfica»: psicoanálisis, cine y epistemología» en CiNéMAS, vol. 14, n 2-3, 2008 , p. 56.

2 Freud, S., Abraham, K., «Carta del 9 de junio de1925», en Correspondencia Freud-Abraham, Paris, Gallimard, coll. «Conocimiento del inconsciente», 1969. 
3 Freud, S., Los delirios y los sueños en la Gradiva de Jensen, 1907, Paris, Gallimard, 1990, p. 141. El subrayado me pertenece.

4 Los dos descompondrán la marcha, el salto, la carrera de hombres y de mujeres para perforar movimientos que no podían distinguirse antes. Muybridge confirmará gracias a su dispositivo, las hipótesis de Marey quien afirmaba que las patas de un caballo, durante las fases de galope, abandonan juntas el suelo una sola vez, algo que era cuestionado por los científicos de la época, hasta esta descomposición lograda por la imagen-movimiento.

5 De acuerdo con este punto de origen, parece interesante señalar una dimensión que puede parecer relativamente anecdótica, y que -tal vez- no lo es tanto. Que el descubrimiento analítico parte del incomprensible cuerpo de la histérica tiene, en esta puesta en paralelo, algo cómico. La histeria es el modo de funcionamiento psíquico que calza perfectamente con la función de comediante. Desde la relación de la histérica con la imagen del cuerpo, y por lo tanto a la puesta en escena del cuerpo, hasta -más fundamentalmente- este deseo del deseo del otro que basa su relación en el otro y en ella misma, la histérica es, por así decirlo, un comediante por «naturaleza». Muchos sujetos histéricos encontrarán en el arte cinematográfico de ficción material para ser material de creatividad dirigido a dilucidar lo real.

6 Dadoun, R., Cine, psicoanálisis y politica, Paris, Séguier, 2000, p. 53.

7 Mérigeau, P., Mankiewicz, Paris, Denoël, 1993.

8 Menciono aquí solo al autor, y exclusivamente al autor, solo las obras y su búsqueda. No puedo ser juez, constituido en investigador de obras fílmicas, del hombre.

$9 \quad$ Citado por R. Dadoun, op. cit., p. 47. El subrayado me pertenece.

10 Kyrou, A., Luis Bunuel, Paris, Seghers, 1962.

11 Op. cit. p. 243-244. El subrayado me pertenece.

12 Ingmar Bergman, Laternamagica, Paris, Folio, 2001, pp. 12-13.

13 También habría que realizar y profundizar un paralelismo, entre la ficción fílmica y el trabajo de ficcionalización, inevitable y necesario para la redacción de casos. Me parece que aportamos algunos elementos a esta pregunta, aunque indirectamente.

14 Esta denominación también tiene como objetivo diferenciar este registro del imaginario de aquel al que fue confinado. Es decir, el imaginario reducido a ilusión y a señuelo. Notemos, sin embargo, aquí brevemente que reducir -como todavía lo escuchamos con bastante frecuencia- el imaginario al registro de la ilusión es al menos reductivo y particularmente problemático tanto en términos de la aprehensión de lo humano, de la psiquis, como lo que resulta en un plano ético y político. En primer lugar, es una restricción de la riqueza lingüística, y por lo tanto del pensamiento, porque si lo imaginario y la ilusión son la misma cosa, eliminemos uno de los dos términos del lenguaje, y al hacerlo-como han demostrado Orwell y Klemperer-reduzcamos el pensamiento y la complejidad de lo real y lo humano. Pero aún más fundamental, aunque correlativamente, reducir la imaginación al registro único de la ilusión implica amputar al hombre de su creatividad que sin la imaginación no podría siquiera desplegarse. Por lo tanto, se estaría también amputarlo su capacidad para pensar que cualquier otra cosa es posible. Amputarlo entonces de su capacidad de innovar, crear e imaginar otra relación consigo mismo y con los demás, otra relación con la convivencia, en resumen, es reducir al hombre a un ser puramente heterónomo. En este tema del simposio, «Memorias y luchas», se puede observar que esta restricción semántica no deja de tener fuertes resonancias en el uso masivo que se hace hoy del término utopía, que sería solo una dulce ilusión sin posibilidad de realización. Esta restricción exclusiva, que en cuanto al término imaginario solo se refiere a una dimensión posible del término, cae exactamente dentro de la lógica de la neolengua. Para la memoria, y parala memoria de las luchas, recordemos lo obvio: si nadie hubiera pensado nunca en utopías, imaginando otras áreas de lo posible, entonces todo habría permanecido inalterable. Por ejemplo, todavía estaríamos debatiendo, -como en el año mil, si las mujeres tienen alma.

15 La Institución imaginaria de la sociedad, Paris, Seuil, 1975, pp. 7-8.

16 Freud, S., (1916-17). Introducción al psicoanálisis, Paris, Payot, 1974, p. 354.

17 Assoun, P. L., “Tratado de la obra psicoanalítica” en Diccionario de las obras psicoanalíticas, Paris, PUF, 2009, p. 81. El trabajo efectuado por Paul-Laurent Assoun sobre las metáforas freudianas es, sobre este tema, edificante, p.p 81-109.

18 En Qué es la filosofía, op. cit. pp. 154-188.

19 Recordemos que el logos no hace referencia solamente a la palabra, a la razón, o a la ciencia, sino también a la relación, a la puesta en relación.

20 Tengamos en cuenta que en este momento cuando las series se vuelven más y más creativas, al menos desde Lynch con Trwin Peacks (1990), y su poder de expresividad reside en gran medida en la duración, el cine conserva la primicia de esta forma de «hybris» de la condensación. Si la condensación trabaja de manera evidente en este modo de expresión fílmica, no lo hace nunca -me pareceen la misma medida y poder cualitativo que en las grandes obras cinematográficas. 
21 Deleuze, G., Guattari, F., Mille Plateanx, Paris, Editions de Minuit, 1980.

22 Metz, C., Le Signifiant imaginaire, Paris, Christian Bourgois, 1979.

23 Se puede ver este cortometraje de $3 \mathrm{mn} 30$ https://www.youtube.com/watch?v=kIOaIGJPmbk, enlace verificado el 2 de mayo de 2018 .

24 ¿O acaso las primeras expresiones del significante no fonemático no toman cuerpo, en el primer espejo del ser, el rostro de la madre?

25 Según mi conocimiento, la primera que utilizó esta expresión fue Julia Kristeva en La revolución del lenguaje poético (1974).

26 Benjamin, W., «La obra de arte en el momento de su reproducibilidad técnica», 1939, en obras III, Paris, Gallimard, 2000 , p. 303.

27 Deleuze, G., Guattari, F., Qué es la filosofía, op. cit., p. 158.

28 Ibid., p. 154.

29 Ibid., p. 155.

30 Respectivamente de Claire Simon (1993) et de Nicolas Philibert (2002).

31 Recordemos, de acuerdo con la fórmula conocida de Lacan, «la schize del ojo y la mirada», la imposibilidad de reducir la mirada a la visión. Lacan, J., El Seminario, Libro XI, Los cuatro conceptos fundamentales del psicoanálisis, París, Le Seuil, 1973 , p. 65.

32 Hago referencia en esta larga frase a un punto que dejo a la eventualidad de una investigación futura. Muy probablemente, existen cuestiones que se prestan más a efectos de confluencia entre cine y psicoanálisis. Las que conciernen al cuerpo, a la imagen, a la imagen del cuerpo, al narcisismo y a lo que las imágenes cinematográficas contienen en abundancia: confluencias, accidentes -buenos y malos-, estados de cambio...

33 Slavoj Žižek en su documental Le guide pervers du cinéma (2006).

34 Benjamin, W., op. cit., pp. 305-306.

35 Sobre ese “espectador" activo, investigador, pensador y emancipado de La sociedad del espectáculo de Debord, ver: Marie José Mondzain, Homo Spectator, Bayard, París, 2007. Jacques Rancière, Le spectateur émancipé, La Fabrique, París, 2008. 